\title{
HUBUNGAN PERILAKU CARING PERAWAT DENGAN KECEMASAN PASIEN PRA OPERASI DI RUANG BEDAH RSUD Dr. H. MOH. ANWAR SUMENEP
}

\author{
Sugesti Aliftitah, Program Studi Ners UNIJA Sumenep \\ e-mail: purples_lovers@yahoo.co.id \\ Emdat Suprayitno, Program Studi Ners UNIJA Sumenep \\ e-mail: emdats@yahoo.com
}

\begin{abstract}
Nurse caring behavior as a moral commitment to protect, maintain and improve the dignity of patients as human beings. The problem of this study is the patient psychological symptoms of anxiety that arise when undergoing surgery, and many patients complain that the nurse is not good when providing services.This study purpose was to analyze the relation between nurse caring behavior with preoperative anxiety patient in bedah ward RSUD dr.H. Moh. Anwar Sumenep.

The study design was Cross Sectional Study. The population all preoperative patients who treated in bedah ward as many as 13 nurses and preoperative patient. The sample sum a 13 nurses and 55 preoperative patients who had fill inclusion criteria by Quota Sampling technique. Independent variable is nurse caring behavior and preoperative patient anxiety as dependent variable.

The results showed that most of the have good caring behavior as 7 nurses (53.8\%) and most of the preoperative patients had low anxiety many as 34 patients (61.8\%). The result of statistic test use Spearman rho befoud $P$ value $<a(0.002<0.05)$. The correlation strength $r$ of 0.783 who has the direction that the strength of the relationship study between vareabel is sturdy. Conclusion in this study be found significant relationship between nurse caring behavior with anxiety preoperative patients in bedah ward RSUD dr. H. Moh. Anwar Sumenep 2017.
\end{abstract}

\section{Keywords: Nurse Caring Behavior, Anxiety preoperative patient}

\section{PENDAHULUAN}

Pembedahan atau tindakan operatif, baik elektif maupun kedaruratan adalah peristiwa kompleks yang menegangkan. Segala bentuk pembedahan tersebut selalu didahului dengan suatu reaksi psikologis pasien yang jelas maupun yang ttidak jelas, normal atau tidak normal yang akhirnya terjadi kecemasan (Smeltzer,and Bare 2001). Pembedahan memiliki dampak terhadap pasien diantaranya dampak fisik dan dampak psikologis, dampak psikologis itu sendiri salah satunya yaitu cemas. Kecemasan adalah respon terhadap suatu ancaman yang sumbernya tidak diketahui, interval, samar-samar atau konfliktual. Kondisi seseorang yang sedang dalam masa pra operasi menunjukan suatu kejadian yang dirasakan penuh ketidak pastian sampai memunculkan rasa cemas, dan sampai terjadi kepanikan, hal ini disebabkan karena adanya gejala psikologis pasien (Stuart et al, 1995).

Perasaan takut dan cemas yang dirasakan pasien bisa dilihat dari tanda dan gejala yaitu meningkatnya denyut nadi dan frekuensi nafas, tidak terkontrolnya pergerakan tangan, lembabnya telapak tangan, resah atau gelisah, pertanyaan yang diulang-ulang, insomnia, selalu buang air kecil (Capernito,2005 dalam Utami, 2015). Gangguan mental yang terbesar. adalah cemas sekitar $20 \%$ dari total populasi penderita kecemasan di dunia (Stuart et al, 2009). Di Indonesia, prevalensi gangguan kecemasan berkisar pada angka 6-7\% dari populasi umum (Smeltzer and Bare, 2001 dalam Arifah, 2012). Hasil survei yang dilakukan Indrawati, dalam penelitiannya tanggal 27 Maret 2015 di Ruang Rawat Inap Teratai RSUD Sidoarjo terdapat 5 pasien pre operasi fraktur ekstremitas bawah 100\% mengalami kecemasan (Idrawati,2015). Hasil penelitian Endang Sawitri di RSUI Kustati Surakarta di dapatkan responden pra bedah yang mengalami cemas ringan sebanyak $(22,4 \%)$, kecemasan yang berat $(13,8 \%)$, jumlah terbanyak yaitu tingkat cemas sedang yang mencapai $(37,9 \%)$, presentase terkecil yaitu cemas sangat berat $(3,5 \%)$ dari seluruh 
jumlah total responden (Sawitri, 2008). Hasil studi pendahuluan di RSUD Sleman pada tahun 2011 menggunakan instrumen skala HARS didapatkan pasien pre operasi yang mengalami kecemasan 54,8\% dari 31 responden (Arifah, 2012). Berdasarkan observasi yang dilakukan dengan menggunakan "Skala Hars" di ruang bedah rumah sakit dr.H. Moh. Anwar Sumenep terdapat 10 pasien pra operasi yang cemas, cemas ringan 2 orang sedangkan yang cemas sedang 7 orang dan 1 satu orang cemas berat.

Proses pembedahan adalah pengalaman yang dapat menyebabkan kecemasan, Kecemasan terkadang berkaitan dengan berbagai prosedur lain yang harus dilakukan pada pasien serta bahaya dan resiko yang ditimbulkanoleh tindakan pembedahan. Pasien yang cemas terdapat bebrapa gejala yaitu emosi, insomnia, gelisah, lemah, gampang menangis dan sulit nyenyak ketika tidur (Utami, 2015). Beberapa faktor yang juga menyebabkan kecemasan pasien pra operasi yaitu tidak mengerti tentang prosedur anastesi, trauma pada nyeri, penyebab kematian, kurang pengetahuan tentang deformitas dan penyebab lainnya pada citra tubuh yang menyebabkan terjadinya kecemasan (Smeltzer and Bare,2001).

Kecemasan pra operasi berdasarkan uraian di atas tidak jarang dihubungkan pada pengetahuan yang salah tentang prosedur pembedahan maupun kurangnya informasi tentang dampak pre, intra dan post operasi. Peran perawat diharapkan dapat mengkaji lebih dalam serta mampu memberikan edukasi atau pendidikan pra operasi yang memadai bagi pasien sehingga kecemasan dapat ditoleransi, Kekhawatiran-kekhawatiran yang nyata atau tidak jelas tersebut perlu mendapat perhatian dari perawat dengan cara menerapkan perilaku 'caring' terhadap pasien pra operasi dengan cara memberikan kepedulian baik secara verbal maupun nonverbal dan memahami terhadap pasien supaya dia bisa mengungkapkan perasaan atau pemahamannya, serta memberikan informasi yang tepat pada perawat untuk membantu menyingkirkan kekhawatiran pasien tersebut. Perawat membutuhkan kompetensi khusus serta kepedulian sosial meliputi kemempuan intelegensi, teknikal, serta interpersonal yang terdapat didalam tindakan 'caring' maupun rasa sayang dan rasa cinta dalam melakukan kommunikasi terhadap orang lainnya (Johnson dalam Nasir, 2009).

\section{BAHAN DAN CARA PENELITIAN}

Penelitian ini merupakan jenis Cross Sectional untuk mengetahui hubungan perilaku caring perawat dengan kecemasan pada pasien pra operasi di ruangan bedah RSUD dr. H. Moh. Anwar Sumenep. Jumlah sampel pada penelitian ini adalah 13 orang perawat dan 55 pasien pra operasi di ruang bedah RSUD dr. H. Moh. Anwar Sumenep mulai tanggal 02 mei sampai 29 Mei-2017 yang memenuhi kriteria inklusi. Kriteria inklusi Perawat yaitu: bersedia menjadi respoden, berusia 22-70 tahun, pendidikan minimal DIII Keperawatan. Kriteria ekslusi yaitu: Perawat yang sedang orientasi, mahasiswa praktek. Kriteria inklusi pasien yaitu: Pasien pra operasi, pasien yang akan menjalani proses operasi dalam waktu dekat, pasien yang dirawat di ruang bedah lebih dari 1 hari, pasien dengan kesadaran penuh. Kriteria eksklusi yaitu: Pasien yang dirawat diruang bedah dengan gangguan jiwa, Pasien yang diberikan sedatif atau obat-obatan penurun kesadaran.

\section{HASIL PENELITIAN}

Tabel 1 Perilaku caring perawat di Ruang Bedah RSUD dr. H. Moh. Anwar Sumenep Tahun 2017

\begin{tabular}{ccc}
\hline Perilaku caring & Jumlah & Prosentase \\
\hline Baik & 7 & $53,80 \%$ \\
Cukup & 2 & $15,40 \%$ \\
Kurang & 4 & $30,80 \%$ \\
\hline
\end{tabular}

Berdasarkan tabel 1 menunjukkan bahwa perilaku caring perawat di Ruang Bedah dari 13 responden sebagian besar berperilaku caring baik sebanyak 7 (53,8\%).

Tabel 2 Kecemasan pasien pra operasi di Ruang Bedah RSUD dr. H. Moh. Anwar Sumenep Tahun 2017

\begin{tabular}{ccc}
\hline kecemasan & Jumlah & Prosentase \\
\hline Berat & 5 & $53,80 \%$ \\
Sedang & 16 & $15,40 \%$ \\
Ringan & 34 & $30,80 \%$ \\
\hline
\end{tabular}

Berdasarkan tabel 2 menunjukkan bahwa kecemasan pasien pra operasi di ruang bedah dari 55 responden sebagian besar pasien pra 
operasi mengalami kecemasan ringan sebanyak $34(61,8 \%)$.

Tabel 3 tabulasi silang perilaku caring perawat dengan kecemasan pasien pra operasi di Ruang Bedah RSUD dr. H. Moh. Anwar Sumenep Tahun 2017

\begin{tabular}{ccccc}
\hline \multirow{2}{*}{ Kecemasan } & \multicolumn{3}{c}{ Perilaku Caring } & \multirow{2}{*}{ Perawat } \\
\cline { 2 - 4 } & Baik & Cukup & Kurang & \\
\hline Berat & 0 & 1 & 3 & 4 \\
Ringan & 3 & 1 & 1 & 5 \\
Sedang & 4 & 0 & 0 & 4 \\
Total & 7 & 2 & 4 & 13 \\
\hline
\end{tabular}

Berdasarkan tabel 3 menunjukkan tabulasi antara perilaku caring perawat dengan kecemasan pasien pra operasi didapatkan jika perilaku caring semakin baik selama perawat memberikan pelayanan maka kecemasan pasien pra operasi semakin ringan atau bisa ditoleransi.

Tabel 4 Uji spearmans rho hubungan perilaku caring perawat dengan kecemasan pasien pra operasi di Ruangan Bedah RSUD dr. H. Moh Anwar Sumenep Tahun 2017.

\begin{tabular}{lcc}
\hline Variabel & Perilaku caring & Kecemasan \\
\hline Perilaku caring & 1.000 & .002 \\
Kecemasan & .002 & 1.000 \\
\hline
\end{tabular}

Dari uji spearman's rho didapatkan $\mathrm{P}<0.005$ berarti Ho ditolah dan $\mathrm{H} 1$ diterima jadi dapat disimpulkan bahwa terdapat hubungan antara perilaku caring perawat dengan kecemasan pasien pra operasi di Ruangan Bedah RSUD dr. H. Moh. Anwar Sumenep Tahun 2017.

\section{PEMBAHASAN}

\section{Perilaku Caring Perawat}

Berdasarkan hasil penelitian ini menjelaskan jika sebagian besar perawat di ruangan bedah RSUD dr. H. Moh. Anwar Sumenep berperilaku caring baik. Watson dalam Yuliawati (2012) Caring merupakan bagian inti keperawatan sebagai perbedaan dengan profesi lain, sebagai komitmen moral dalam perlindungan, dan untuk melindungi martabat manusia. Perilaku ini diterapkan melalui kejujuran, kepercayaan, dan niat baik. Perilaku caring memerikan pertolongan pada pasien dan keluarganya untuk peningkatan yang baik dalam segi, psikologis, fisik, sosial serta spiritual. Potter \& Perry dalam Yuliawati (2012) menjelaskan bahwa berperilaku caring bukan terbentuk otomatis pada seseorang, melainkan adalah hasil budaya, nilai-nilai, pengalaman, serta hubungan seseorang dan orang lainnya. Perawat dalam berperilaku pada pasien pasti ada perbedaan menyesuaikan dengan akan kebutuhan, permasalahan serta kepercayaan pasien. Perawat dalam penerapan perilaku caring harus melihat dan menyesuaikan unsur nilai dan budaya pasien.

Berdasarkan hasil penelitian sebelumnya yang dilakukan oleh Dhika Setiyawan (2014) "Hubungan Perilaku Caring Perawat Dengan Tingkat Kecemasan Ibu Akibat Hospitalisasi Anak (Usia 0- 12 Tahun) Di Ruang Rawat Inap Anak RSUD Ambarawa Kabupaten Semarang". variabel perilaku caring perawat yang dipersepsikan ibu menunjukkan jika perawat yang dinilai telah mempunyai perilaku caring yang baik. Hasil penelitian yang dilakukan oleh Ade Lisna Yuliawati (2012) tentang "Gambaran perilaku Caring Perawat Terhadap Pasien Di Ruang Rawat Inap Umum RS Dr. H. Marzoeki Mahdi Bogor" menunjukkan jika perilaku Afektif dan perilaku Caring Perawat baik. Penelitian Nurlaili Hidayanti (2013) tentang "Hubungan Perilaku Caring Perawat Dengan Tingkat Kecemasan Pasien Rawat Inap Di Rumah Sakit PKU Muhammadiyah Surakarta" Sebagian besar perilaku caring perawat baik. Melihat betapa besar manfaat caring perawat terhadap pasien, maka seharusnya perilaku caring tersebut selalu tercermin dalam diri setiap perawat dalam berinteraksi

terhadap pasien apalagi bagi pasien yang akan menjalani proses tindakan medis berupa operasi tentunya sangat membutuhkan caring dari perawat agar supaya bisa menguragi dan mencegah terjadinya dampak negatif yaitu salah satunya dampak psikologis berupa cemas, karena caring perawat merupakan esensi dari keperawatan. Pendidikan perawat dan masa kerja perawat tentunya sangat berpengaruh terhadap terciptanya perilaku caring. Selain kepada pasien, perilaku caring memiliki dampak yang sangat besar bagi rumah sakit yaitu memberikan citra yang tingga di mata msyarakat serta menjadikan profesi keperawatan memilki bagian khusus menurut sudut pandang pemakai jasa pelayanan kesehatan pasien dimana sangat membutuhkan bantuan perawat 
yang berupa perhatian perawat dengan berperilaku care.

\section{Kecemasan Pasien Pra Operasi}

Berdasarkan hasil penelitian menunjukkan bahwa kecemasan pasien pra operasi di ruang bedah RSUD dr. H. Moh. Anwar Sumenep Tahun 2017 sebagian besar responden mengalami kecemasan ringan. Videback (2008) Kecemasan merupakan rasa takut yang tidak jelas dan tidak ditunjang oleh situasi, pada saat merasa cemas seseorang merasa takut dan mempunyai perasaan akan mengalami musibah padahal tidak tau kenapa emosi yang mengancam tersebut terjadi, tiada objek yang teridentifikassi sebagai rangsangan rasa cemas. Stuart Sundeen dalam Utami (2015) Kecemasan merupakan reaksi akibat suatu bahaya yang penyebabnya tidak diketahui, interval, tidak jelas atau konfliktual. Kondisi seseorang yang preoperasi menunjukan suatu kejadian yang dialami dengan penuh ketidak jelasan yang menyebabkan kecemasan, serta berlanjut pada kepanikan, karena pembedahan bisa menyebabkan dampak psikologis pada pasien.

Hasil penelitian yang dilakukan oleh Fadhila Anik Arbani (2015) tentang "Hubungan Komonikasi Terapiutik dengan Tingkat Kecemasan pasien Pra Operasi di RS PKU Muhammadiyah Sukoharjo" menyatakan bahwa terdapat pasien pra operasi mengalami kecemasan sedang. Hasil penelitian yang di lakukan oleh Nur Hasanah (2014) tentang "Hubungan Antara Komonikasi Terapiutik dengan Tingkat Kecemasan Pasien Pra Operasi Sectio Caesarea Di Ruang Ponek RSUD Karang anyar" didapatkan bahwa pasien pra operasi yang mengalami kecemasan ringan. Penelitian Nurlaili Hidayanti (2013) tentang "Hubungan Perilaku Caring Perawat Dengan Tingkat Kecemasan Pasien Rawat Inap Di Rumah Sakit PKU Muhammadiyah Surakarta" menunjukkan bahwa sebagian besar mengalami kecemasan ringan.

Kecemasan pasien pra operasi sangat dipengaruhi oleh perilaku caring perawat pada saat memberikan pelayanan kesehatan, karena pada saat pasien akan menjalani proses operasi akan memiliki gejala psikologis salah satunya yaitu cemas dengan sumber tertentu seperti cemas memikirkan ekonomi, tentang dampak anastesi, ruang operasi serta nyeri dan gangguan fisik setelah masa operasi, dengan hal ini maka diperlukan caring dari seorang perawat agar supaya bisa mengurangi dan mengatasi kecemasan yang dialami oleh pasien yang akan menjalani tindakan medis tersebut, Sehingga dengan diterapkannya caring tersebut selain bisa membantu proses penyembuhan pasien juga bisa meningkatkan mutu pelayanan bagi rumah sakit.

\section{Hubungan Perilaku Caring Perawat dengan Kecemasan Pasien Pra Operasi Di RSUD Dr. H. Moh. Anwar Sumenep Tahun 2017}

Dari hasil analisa statistic dengan uji spearman rho menunjukkan bahwa Ho ditolak yang artinya ada hubungan antara perilaku caring perawat dengan kecemasan pasien pra operasi di RSUD Dr. H. Moh. Anwar Sumenep Tahun 2017. Hasil ini berdasarkan dari hasil uji statistic spearman rho antara perilaku caring perawat dengan kecemasan pasien pra operasi, didapatkan sebagian besar perawat berperilaku caring baik, dan didapatkan sebagian besar pasien pra operasi mengalami kecemasan ringan. Tabulasi silang perilaku caring perawat dengan kecemasan pasien pra operasi juga menunjukkan jika perilaku caring perawat semakin baik maka kecemasan pasien akan semakin ringan.

Perilaku caring yang diberikan oleh perawat serta pelayanan secara holistik dan komprehensif membantu mengurangi kecemasan bagi pasien pra operasi, karena kemampuan dalam memperhatikan pasien serta keahlian intelektual dan interpersonal tergambar didalam perilaku caring perawat. Perilaku caring sangat bermanfaat dalam keperawatan. Perilaku caring tepat untuk pemberian asuhan keperawatan pada pasien, diantaranya bisa dipakai dalam asuhan psikologis pasien (Hidayanti, 2013). Salah satu faktor psikologis itu seperti kecemasan (Stuart, 2006 dalam Hidayanti 2013).

Berdasarkan hasil penelitian sebelumnya dilakukan oleh Nurlaili Hidayanti (2013) tentang "Hubungan Perilaku Caring Perawat Dengan Tingkat Kecemasan Pasien Rawat Inap Di Rumah Sakit PKU Muhammadiyah Surakarta" maka disimpulkan adanya korelasi antara perilaku caring perawat dengan 
kecemasan pasien di Rumah Sakit PKU Muhammadiyah Surakarta. Penelitian Dhika Setiyawan tentang "Hubungan Perilaku Caring Perawat Dengan Tingkat Kecemasan Ibu Akibat Hospitalisasi Anak (Usia 0- 12 Tahun). disimpulkan terdapat hubungan antara perilaku caring perawat dengan kecemasan ibu karena hospitalisasi anak di ruang rawat inap anak RSUD Ambarawa. Hasil penelitian Fadhila Anik Arbani (2015) tentang "Hubungan Komonikasi Terapiutik dengan Tingkat Kecemasan pasien Pra Operasi di RS PKU Muhammadiyah Sukoharjo dapat disimpulkan bahwa terdapat hubungan yang signifikan antara komonikasi terapiutik dengan tingkat kecemasan pasien pra operasi di RS PKU Muhammadiyah Sukoharjo.

Perawat yang menerapkan perilaku caring dengan baik hanya terdapat 7 orang dari 13 perawat di ruang bedah, hal itu menjadi faktor dari kecemasan pasien pra operasi karena tidak semua perawat yang menerapkan perilaku caring dengan baik. Kecemasan pasien pra operasi merupakan gejala psikologis yang timbul salah satunya karena ketidak tahuan pasien akan informasi mengenai operasi sehingga menimbulkan kecemasan, untuk itu perlu bagi perawat untuk selalu memenuhi apa yang menjadi kebutuhan pasien dimana semua itu tercermin dalam perilaku caring perawat selama memberikan pelayanan kesehatan kepada pasien secara holistic dan komprehensif.

\section{KESIMPULAN}

1. Perilaku Caring Perawat di Ruang Bedah RSUD dr. H. Moh. Anwar Sumenep dalam kategori perilaku caring baik

2. Kecemasan Pasien Pra Operasi di Ruang Bedah RSUD dr. H. Moh. Anwar Sumenep, ebagian besar responden mengalami kecemasan ringan.

3. Ada hubungan antara perilaku caring perawat dengan kecemasan pasien pra operasi di Ruang Bedah RSUD dr. H. Moh. Anwar Sumenep.

\section{SARAN}

\section{Rumah Sakit}

Hasil penelitian ini diharapkan dapat menjadi masukan bagi pihak manajemen RSUD dr. H. Moh. Anwar Sumenep agar supaya bisa menerapkan dan meningkatkan perilaku caring perawat yang baik, sehingga dengan hal ini dapat meningkatkan mutu pelayanan serta citra rumah sakit.

2. Organisasi Keperawatan

Hasil penelitian ini diharapkan dapat memberikan informasi tentang perilaku caring perawat, dan dengan informasi tersebut juga dapat menumbuhkan kesadaran serta motivasi kepada perawat untuk menerapkan perilaku caring yang baik dalam memberikan asuhan keperawatan kepada pasien.

3. Peneliti

Penelitian ini dapat dikembangkan lebih mendalam lagi terhadap penelitian selanjutnya terkait hubungan maupun pengaruh perilaku caring perawat dengan kecemasan pasien pra operasi.

4. Masyarakat

Penelitian ini diharapkan dapat memberikan informasi terhadap masyarakat sebagai bahan kajian pengetahuan terutama yang berkaitan dengan bidang pelayanan keperawatan. Masyarakat dapat mengetahui perilaku caring perawat yang ada di rumah sakit terutama di ruang bedah, sehingga nantinya mereka juga dapat memberikan masukan dan saran dalam peningkatan layanan keperawatan sesuai harapannya.

\section{DAFTAR PUSTAKA}

Ardiana, Annisah, 2010“Hubungan kecerdasan emosional dengan perilaku caring perawat pelaksana menurut persepsi pasien di Ruang rawatinap $R S U$ Dr. $H$. Kuesna di Bondowoso, Jurnal pendidikan, hlm 8-20.

Dagobercia Uskenat, Maria, Sri, Puguh dan solechan achamad, 2013 "Perbedaan tingkat kecemasan pada pasien pra operasi dengan general anastesi sebelum dan sesudah diberikan relaksasi otot progresif di RS pantiwilasa citarum semarang", Jurnal pendidikan, hlm 30.

Erik, Andrian, Hardiyanto, 2013 "Pengaruh murottal terhadap tingkat kecemasan pasien pra operasi di ruang bedah RSUD dr. H. Moh. Anwar Sumenep", skripsi, hlm 31 .

Hidayanti, Nurlaili, 2013 "Hubungan perilaku caring perawat dengan tingkat kecemasan pasien rawat inap di rumah sakit PKU Muhammadiyah Surakarta",Jurnal pendidikan hlm 66 . 
Kurniyawati, Dini, 2016 "Hubungan perilaku caring perawat dengan kepuasan pasien di puskesmas Bluto kecamatan bluto Kabupaten Sumenep"Skripsi, hlm 10-917.

Nursalam, 2016 "Metode logi penelitian ilmu keperawatan", Jakarta, Salemba Medika.

Nasir, Abdul, dkk, 2009 "Komonikasi dalam keperawatan”, Jakarta, Salemba Medika.

Sawitri, endang, Ida Nuriala Trise, dan sudaryanto agus 2012 "pengaruh pemberian informasi tentang persiapan operasi dengan pendekatan komunikasi terapeutik terhadap tingkat kecemasan pasien pre operasi di ruang bougenville RSUD sleman Yogyakarta". Jurnal Pendidikan, Vol. IV, No. 01, hlm 1-2.

Smeltzer, dkk 2001, Buku ajar KeperawatanMedikal Bedah, EGC Jakarta

Sawitri, Endang, 2008 "pengaruh pemberian informasi prabedah terhadap tingkat kecemasan pada pasien pra bedah mayor di bangsa lortho pedirsui kustat, hlmi Surakarta”Junal pendidikan, hlm 26-27.

Setiyawan D, 2014 “ Hubungan Perilaku Caring Perawat dengan tingkat kecemasan ibu akibat hospitalisasi anak (usia 0-12 tahun) di ruang rawat inap anak RSUD Ambarawa Kabupaten Semarang”Jurnal pendidikan hlm 66.

Stuart, Gail W, 2006 "buku saku keperawatan jiwa edisi 5”, Jakarta, EGC

Stuart, Gail W, 2009 " pcykiatric nursing”,jakarta, EGC

Utami, Dwi, Endah .2015 "hubungan sikap perawat dalam memberikan informasi dan pengetahuan pasien yang mempengaruhi tingkat kecemasan pada pasien pre operasi elektif mayor di RSUD $d r$. Soedirman kebumen". Jurnal Pendidikan, hlm 1-26

Videbeck, Seila L, 2008“buku ajar keperawatan jiwa", EGC Jakarta..

Yuliawati, 2012, " Gambaran perilaku caring perawat terhadap pasien di ruang rawat inap umum RS DR. H. Marzoeki Mahdi Bogor". Jurnal pendidikan, hlm1-19. 